\title{
Development and Application of Investment Plan Management System
}

\author{
He Chen ${ }^{\mathrm{a} *}$, Hong Bai ${ }^{\mathrm{b}}$, Zhidong Wang ${ }^{\mathrm{a}}$, Hui li ${ }^{\mathrm{a}}$, Jianqin Liu ${ }^{\mathrm{a}}$, Jun li ${ }^{\mathrm{a}}$ \\ ${ }^{a}$ State Power Economic Research Institute, No. 8 Nanhengdong Street Xicheng District, Beijing 100052, China \\ ${ }^{b}$ China Electric Power Research Institute, No. 15 Xaiying Rd(E), Qinghet, Beijing 100192, China
}

\begin{abstract}
Large amount of investment will be put into power infrastructure to fulfill electric power demand now and in the near future. Without the help of information technique, investment plan management will become very difficult. This paper presents the software development and industrial application of Investment Evaluation System (IPMS) systematically. Firstly, overall architecture of IPMS is provided. Then detailed information involving business, application, data, and technique aspects specific for power industry is presented. With the understanding of processes and fundamental elements of systemic architectures, IPMS can be designed accordingly. Operation interface, hardware deployment and industrial application are also provided.
\end{abstract}

Keywords: Investment plan management, software development, power industrial application

\section{Introduction}

China's power industry is entering a new stage of cross-regional interconnections striding toward a nationwide interconnected grid for optimizing resources disposition on a large scope, e.g. the rapid development of Ultra High Voltage (UHV) transmission [1]. With the aim of strengthening the construction of strong and smart power grid, large investment has and will be put into power infrastructure. In order to put the right investment into the right place on the right time, investment plan management becomes imperative.

Investment has different meanings in finance and economics, e.g., finance investment is putting money into something with the expectation of gain, which upon thorough analysis, has a high degree of security for the principal amount, as well as security of return [2]. In power industry, investment often means to put money into power infrastructure, such as power plant, transmission line, power transformer, substation, etc. Investment plan management for large power company is a complex analysis and decision procedure, an important aspect of which concerns with total-amount decision (headquarter side) and its allocation (subsidiary side) based on the results of investment post-evaluation [3].

Investment plan management is complex inherently in management modes, information interaction, data as well as the articulation. Without the support of information technique, plan management will be very difficult to be realized. The development of Investment Plan Management System (IPMS) will meet the demand. It will cooperate the headquarters with its subsidiaries, realize standardized process management, information collection, plan determination, adjustment and issue out, etc. At the same time, IPMS should has appropriate data control, strict data validation and flexible data query, timely report generation and information transmission.

IPMS is not an independent platform, it has the capability to be easily integrated into a Unified Information Platform [3]. It will be the integration of management science and systems engineering based

\footnotetext{
* Manuscript received June 12, 2012; revised August 16, 2012.

Corresponding author. Tel.: 86-10-63411747; E-mail address: chenhe@chinasperi.sgcc.com.cn.
} 
on reliable information technology, such as "SG186" [4], which can coordinate different kinds of information resource and create the foundation for practical application of IPMS.

This paper presents some important aspects of the development and application of IPMS. The organization is as follows. In section 2, the overall architecture of IPMS is provided. Four critical architectures are presented separately from section 3 to 6 . The operation interface of IPMS is given in section 7. The hardware deployment and industrial application are presented in section 8. Finally, the work of this paper is summarized in the last section.

\section{Overall Architecture}

The overall architecture of IPMS includes four parts: business, application, data and technique, as shown in Fig. 1.

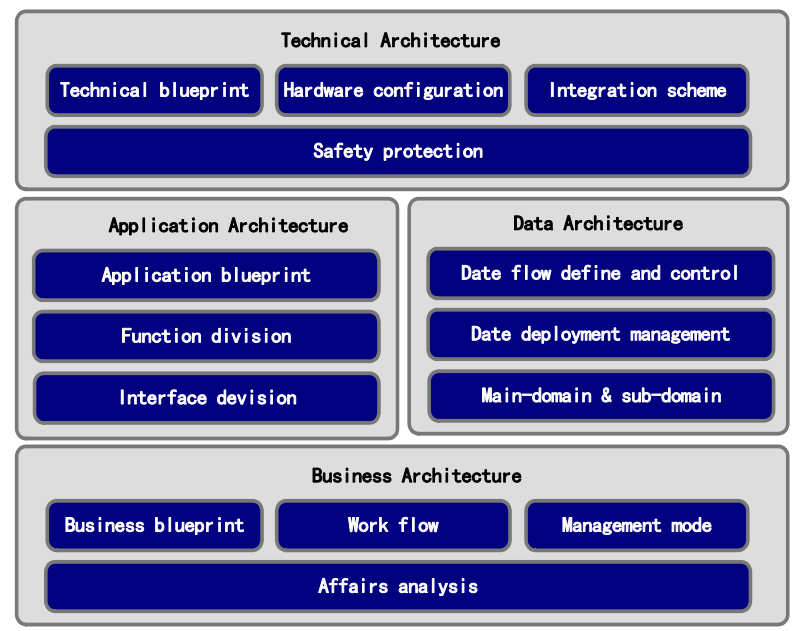

Fig. 1. Overall architecture of IPMS.

- Business architecture is to analysis and construct IPMS from a business point of view, based on the requirements came from headquarter, subsidiaries and other participants.

- Application architecture is based on business architecture, to define the scope of application and specific functions.

- Data architecture is based on the business architecture to precisely define data sources, data classification, data flow, and data deployment from the viewpoint of system requirement.

- Technical architecture, based on the application and data architecture, realizes overall technical implementations corresponding to the development of information technology and practical experience.

\section{Business Architecture}

Business architecture is a blueprint of the enterprise that provides a common understanding of the organization and is used to align strategic objectives and tactical demands. Business architecture articulates the functional structure and relationship of an enterprise in terms of its business services, information and work flow. The specific business blueprint of IPMS is shown in Fig. 2.

In business services part, suggestive plan is a report procedure from subsidiaries to headquarter, while plan management is contrary, plan adjustment is an interaction procedure, and start-up management means that it permits to carry out a specific project if all external conditions are in place, in other words, the investment can be put on this project. In business data, it has project päkage, project and work. In power industry, project can be pointed as construction of transmission lines and transformers from power plant to energy consumer, work points to a specific part of this project, such as build a $500 \mathrm{kV}$ transmission line. Often power projects should be authorized by the government, so the packaging of project is necessary based on special purpose and region. 
Work flow of business architecture is shown in Fig. 3. In practice, this procedure will be performed many times. Aid in Decision Making (ADM) carries out comprehensive inquiry and advanced analysis to facilitate investment decision.

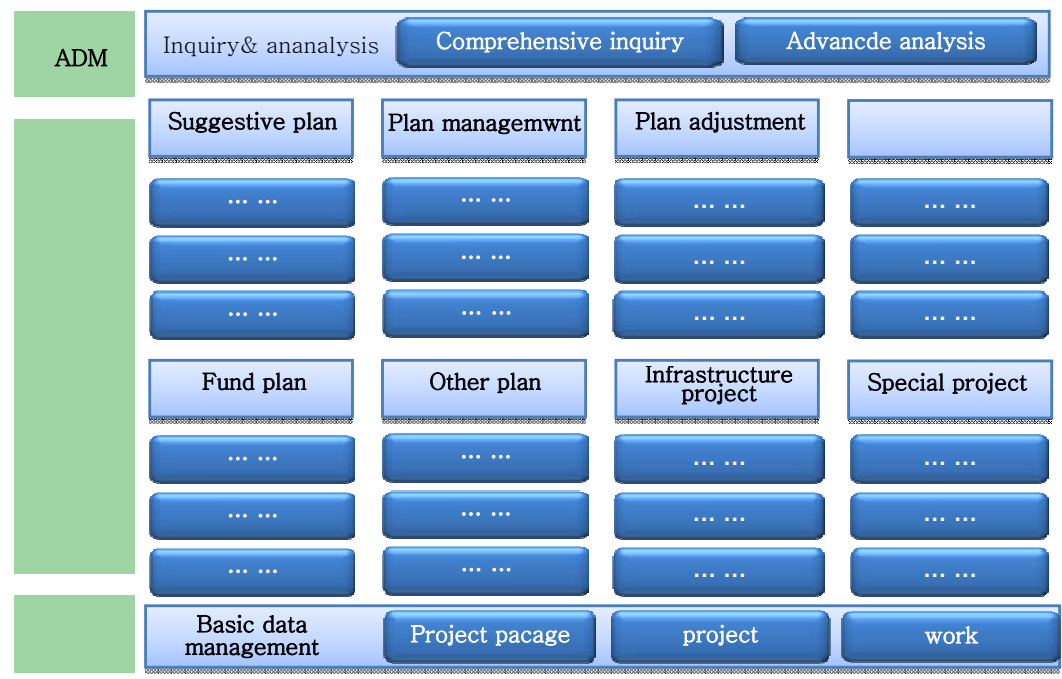

Fig. 2. Business blueprint.

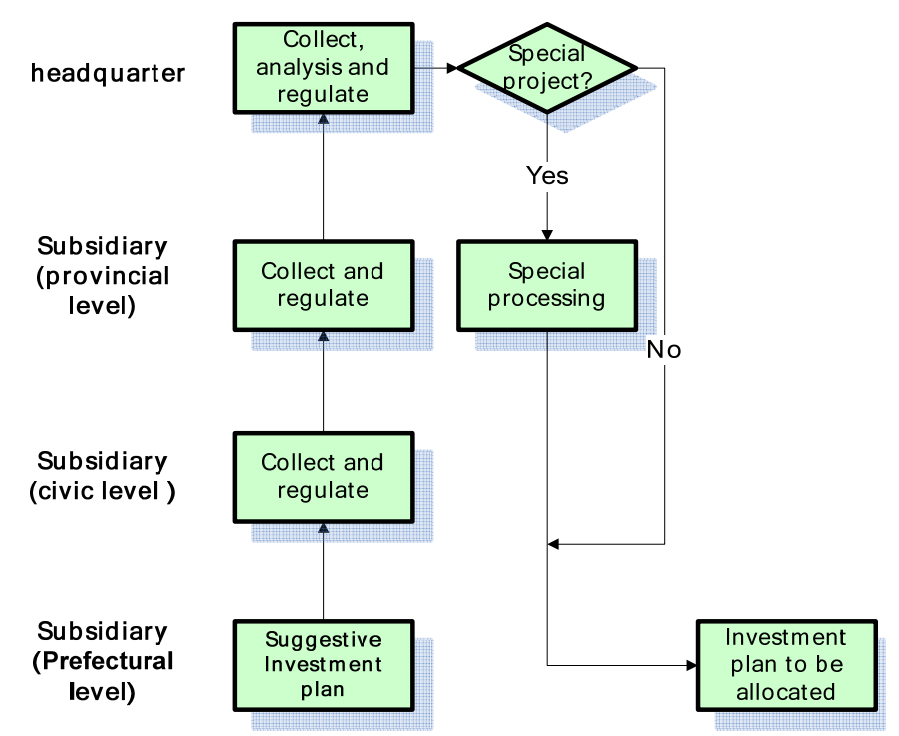

Fig. 3. Work flow.

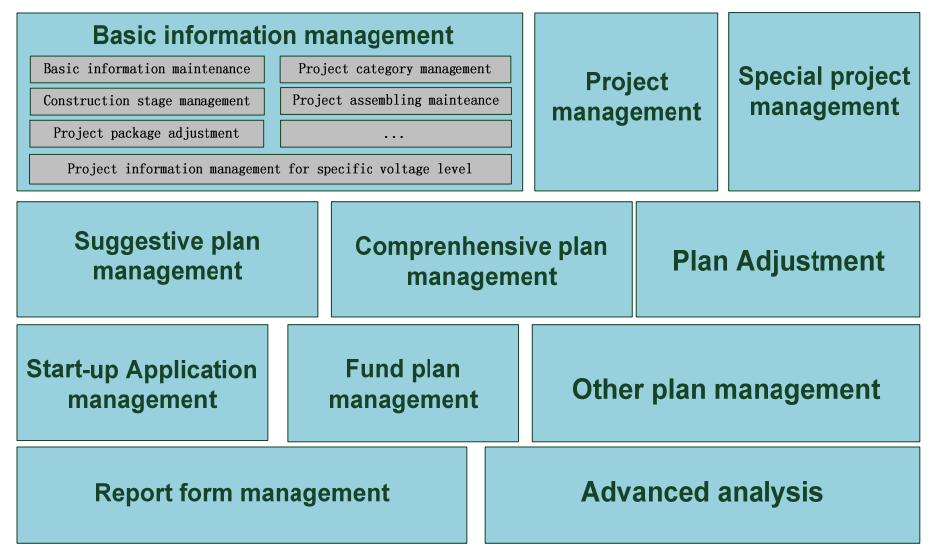

Fig. 4. Application blueprint. 
Table 1. Function division

\begin{tabular}{|c|c|c|c|}
\hline No. & Level 1 & Level 2 & Descriptions \\
\hline 1.1 & \multirow{5}{*}{$\begin{array}{l}\text { Basic management } \\
\text { information }\end{array}$} & $\begin{array}{l}\text { Basic information } \\
\text { maintenance }\end{array}$ & Maintain project package, project and work \\
\hline 1.2 & & Stage maintenance & year for start-up and finished \\
\hline 1.3 & & Package adjustment & Adjust project to build new package \\
\hline 1.4 & & Categories maintenance & $\begin{array}{l}\text { Categories defined based on different } \\
\text { functions, including main-network strengthen } \\
\text { project, power source delivery project, etc. }\end{array}$ \\
\hline$\cdots$ & & $\cdots$ & $\cdots$ \\
\hline
\end{tabular}

\section{Application Architecture}

Applications architecture is specified on the basis of power industry requirements. This involves defining the interaction between application packages, databases, and middleware systems in terms of application blueprint, function division, etc. It manages how multiple applications are poised to work together.

Application blueprint is shown in Fig. 4, in which the special project management is to cope with the emergency situation, such as it needs to build a distribution system to meet a suddenly increased load demand, its investment should be considered timely. Detailed information about function division is listed in Table 1.

\section{Data Architecture}

Essential to realizing the target state, data architecture describes how data is processed, stored, and utilized in the system. It provides criteria for data processing operations that make it possible to design data flows and also control the flow of data in the system.

Data flow of IPMS is shown in Fig. 5, in which project package, project and work exchange information between each other as well as other parts.

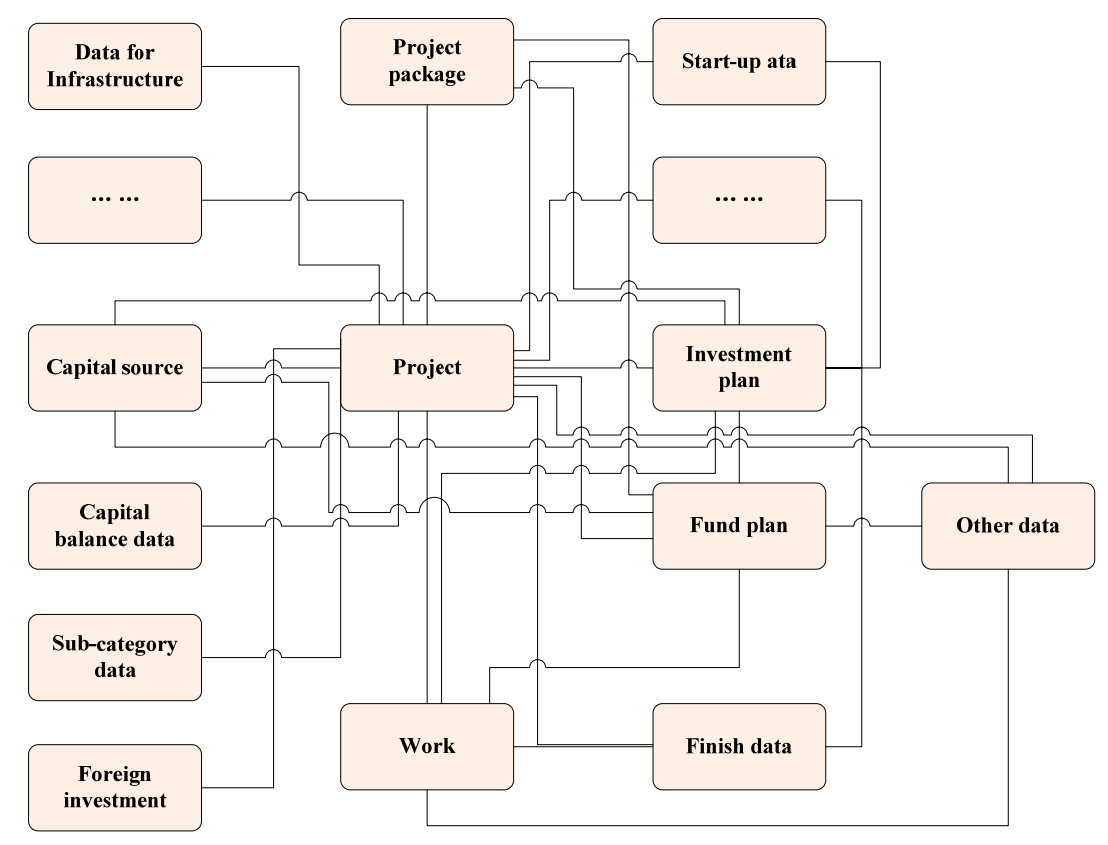

Fig. 5. Date flow 


\section{Technical Architecture}

Technical architecture works with the overall behavior of the infrastructure of the technical environment, the software environment, as well as the networking environment, etc. It has the capability of accessing data and carrying out information exchange to meet the requirements of IPMS.

External technical architecture is shown in Fig. 6, on NetWeaver platform, the mainline synchro and mainline interface are encapsulation based on standard web service. Through standard SOAP/HTTP protocol, external data exchange can be realized. For power cooperation, investment plan is an integrated part of a whole "chain", which often starts from planning and end to statistic. At the same time, IPMS should connect to Enterprise Resource Planning (ERP) engineering management [5] and finical management, in order to be integrated into the whole informationization procedure.

Internal technical architecture of IPMS uses standard B/S pattern and J2EE architecture to achieve multi-tier distributed application. Application development uses component-style development and management, making the system easier to manage, develop, and maintain. Well-known SSH (struts+spring+hibernate) architecture is used to realize the whole system.

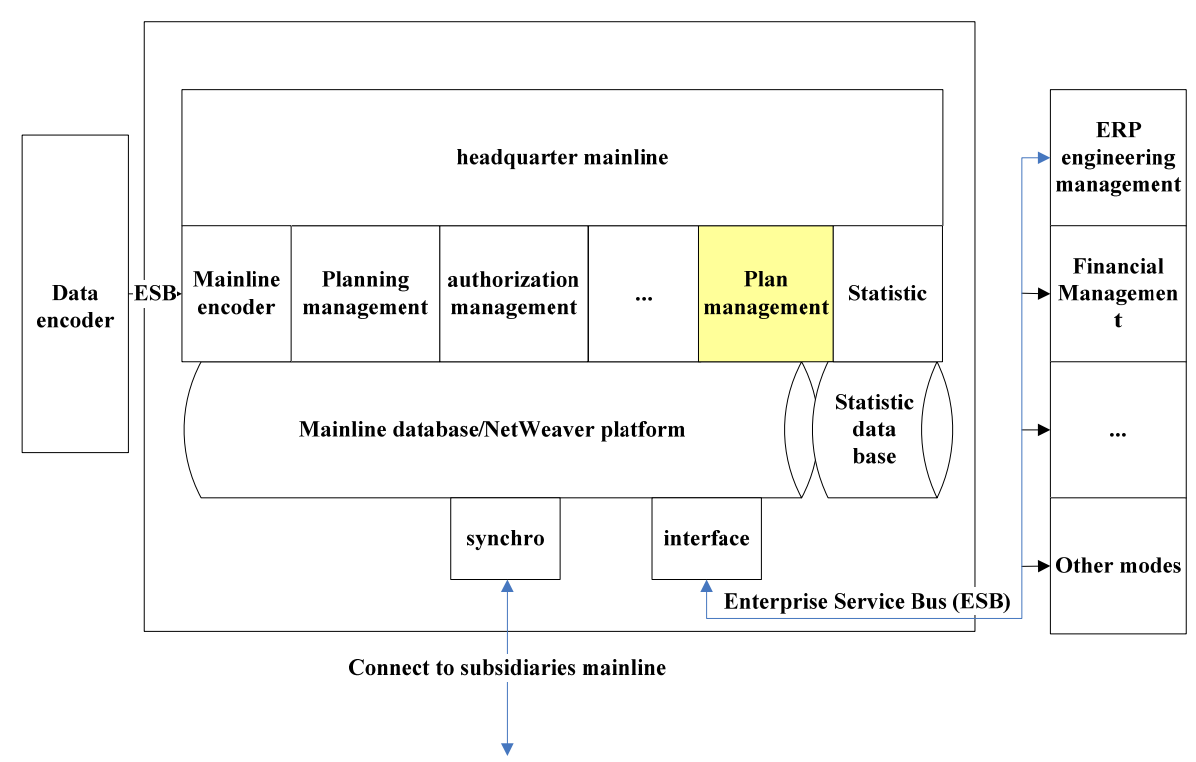

Fig. 6. External technical architecture

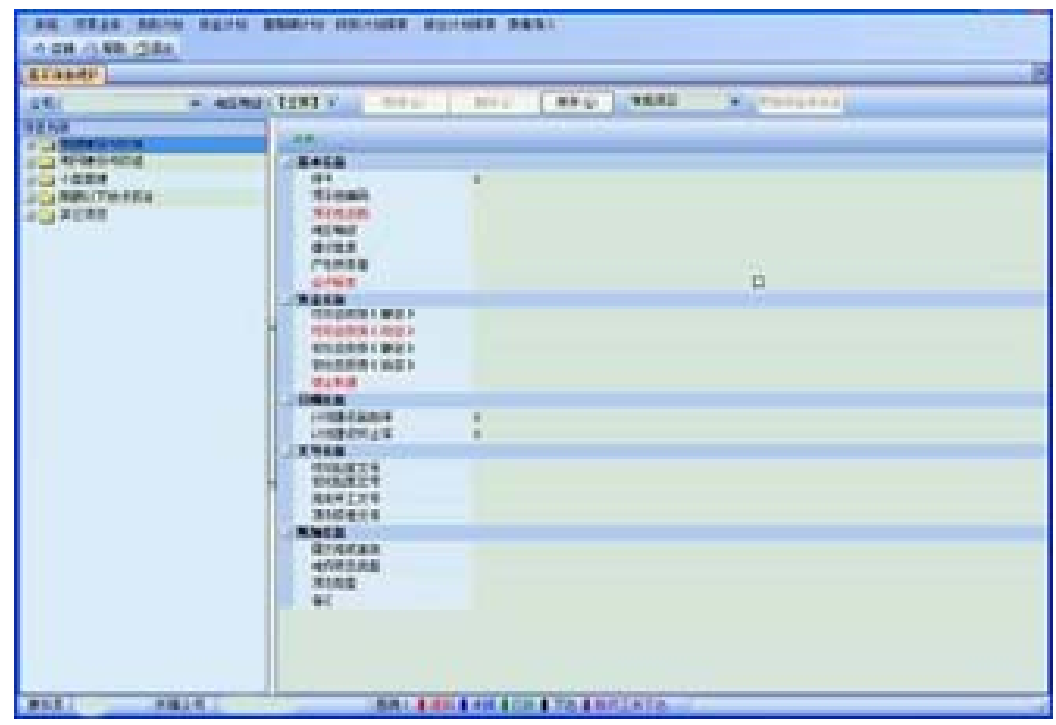

Fig. 7. Operation interface of IPMS. 


\section{Operation Interface of IPMS}

Operation interface of IPMS is shown in Fig. 7, which has a relatively good human-computer interface, providing functions such as data entry, data modification, query reporting, data issue, and report form generation, etc. Suggestive plan determination, plan adjustment, data transmission and exchange can be easily realized.

\section{Hardware Deployment and Industrial Application}

Hardware deployment is shown in Fig. 8, where storage area network (SAN) provides access to consolidated, block level storage. It is a high-speed special-purpose network which interconnects different kinds of data storage devices with associated data servers. Local area network (LAN) connects computers and devices with higher data-transfer rates and sharing application resources. LAN connects to WAN through information center.

After many years of development and enhancement, IPMS has been established and adopted by many big business users for their investment plan management in 2011 successfully. The IPMS is a system to be continuously improved to meet the new requirements of the customers..

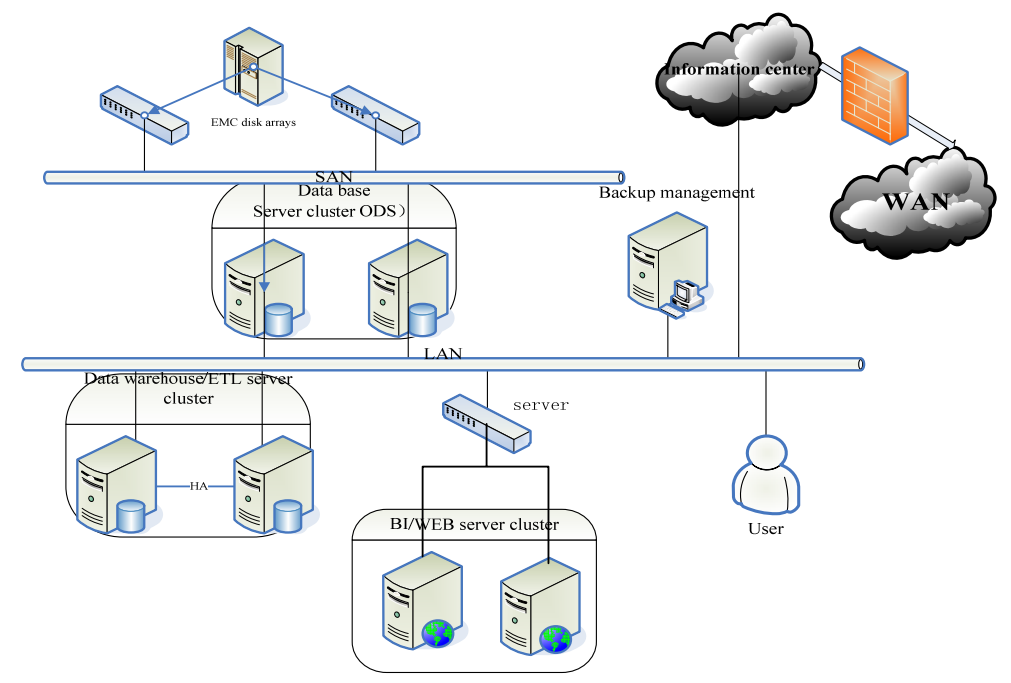

Fig. 8. Hardware deployment.

\section{Conclusions}

The development of IPMS is necessary in order to arrange large scale of investment to be put on power infrastructure. Some important aspects involving business, application, data and technical architectures are presented. Blueprint of business architecture provides common understanding of the organization, and work flow indicates the business relationship between headquarter and subsidiaries. Applications architecture gives a completed application division and detailed functional description. Data flow of IPMS illustrates the information exchange between different data modules. Technical architecture gives the external procedure framework and internal technical realization. With systemic design, IPMS can be easily realized, and it has user-friendly operation interface, standard hardware deployment and successful industrial application.

\section{Acknowledgements}

This work was supported by State Grid Corporation of China, Major Projects on Planning and Operation Control of Large Scale Grid (SGCC-MPLG002-2012). And the authors thank Quan Zhang, Zichen Zhao of State Grid Cooperation of China, Quanling Zhang and Peng Shan of Hangzhou Telek Technology Co., Ltd for their contributions on IPMS. 


\section{References}

[1] Huang DC, Shu YB, Ruan JJ, Hu Y. Ultra high voltage transmission in China: developments, current status and future prospects. Proceedings of the IEEE, 2009; 97(3):555-583.

[2] Graham B and David D. Security Analysis. McGraw-Hill Book Company, 1951.

[3] Chen $\mathrm{H}$, et al. Investment evaluation system development based on unified information platform for future smart grid. Energy Procedia; 2011; 12:10-17.

[4] Zhang J, Li LZ. Studies and discussions of smart terminal for electric utilization. In: Proc. of China International Conference on Electricity Distribution, 2010:1-6.

[5] Liu S. Problems and solutions in ERP applications in electric power company. Electric Power Technologic Economics, 2009; (3):69-72. 